\title{
Self-reported health following percutaneous coronary intervention: results from a cohort followed for 3 years with multiple measurements
}

This article was published in the following Dove Press journal:

Clinical Epidemiology

3 December 2014

Number of times this article has been viewed

\author{
Karin Biering ${ }^{1,2}$ \\ Morten Frydenberg ${ }^{3}$ \\ Niels Henrik Hjollund ${ }^{4,5}$ \\ 'Department of Occupational \\ Medicine, Regional Hospital West \\ Jutland, Herning, Denmark; ${ }^{2}$ Danish \\ Ramazzini Centre, Regional Hospital \\ West Jutland, Herning, Denmark; \\ ${ }^{3}$ Section of Biostatistics, Department \\ of Public Health, Aarhus University, \\ Aarhus, Denmark; ${ }^{4}$ WestChronic, \\ Regional Hospital West Jutland, \\ Herning, Denmark; ${ }^{5}$ Department \\ of Clinical Epidemiology, Aarhus \\ University Hospital, Aarhus, Denmark
}

Correspondence: Karin Biering Department of Occupational Medicine, Regional Hospital West Jutland, DK-7400 Herning, Denmark

$\mathrm{Tel}+4578433518$

Email karin.biering@vest.rm.dk
Objective: Improvements in the treatment of coronary heart disease have increased the number of patients living with a chronic heart disease. Patient-reported outcomes are required to adequately describe prognosis. We report self-rated health in a population-based cohort of patients with coronary heart disease treated with percutaneous coronary intervention (PCI).

Methods: Over 3 years, we followed 1,726 patients under 65 years treated with PCI with eight repetitive questionnaires. With the use of multiple imputation, we described the course of self-rated health using the short form 12-item survey's mental component summary (MCS) and physical component summary (PCS) and analyzed adjusted differences by sex, age, educational level, indication for PCI, and left ventricular ejection fraction along with an analysis of decrease in health status.

Results: MCS scores increased during follow-up, while PCS scores were stable over time. Men rated higher in MCS and PCS than women, and older patients rated higher in MCS than younger. Other differences were negligible. Younger age was identified as a risk factor for marked decrease in mental health over time.

Conclusion: In a complete population-based cohort of PCI patients with multiple measurements, we found improvements in mental, but not physical health over time. Demographic differences in health were larger than disease-related differences.

Keywords: coronary heart disease, patient reported outcomes, multiple imputation, longitudinal study

\section{Introduction}

Coronary heart disease is a major cause of death in most parts of the world. In Denmark approximately 9,000 patients are treated annually with percutaneous coronary intervention (PCI), of which 2,500 are less than 65 years of age. ${ }^{1}$ Mortality has declined due to improvements in treatments, resulting in more people living with heart disease as a chronic condition. ${ }^{2}$ Prognosis in terms of mortality and readmissions is well described in the literature, but prognosis in terms of wellbeing and impairments in everyday life is important as well. This raises a need for studies assessing patient-reported outcomes, to provide important information about health and wellbeing following heart disease. The prognosis regarding both return-to-work, recurrent cardiovascular events, and mortality has previously been found to be associated with self-reported health, and patient-reported outcomes are important measures in predicting prognosis. ${ }^{3-9}$ Most previous studies of self-reported health after coronary heart disease measured self-reported health only once or twice after the PCI, ${ }^{10-15}$ but also a few studies with repetitive follow-up measurements have been conducted, with up to six measurement 
points over a follow-up time of up to 3 years. ${ }^{16-19}$ The largest study with multiple measurements included 1,149 patients followed over 3 years with seven measurement points. ${ }^{20}$ Most studies report improvement in health status in the first 6 months after which a stable level is reached. These findings applied to physical, mental, and social domains. Most studies have reported group mean changes, while a few studies also analyzed intra-individual changes. ${ }^{10,11}$ In these studies, the proportion of patients who increased, declined, or were unchanged is reported, but different definitions of change make the results difficult to compare.

None of the identified previous studies included nonrespondents and patients lost to follow-up in the analysis, posing a threat to the external validity. Moreover, previous studies often report on selected populations, such as patients included in randomized controlled trials.

With this study, we sought to provide a valid and detailed description and analysis of the long-term course of selfreported health in a large population-based cohort of younger PCI patients with a high number of repetitive measurement points and a thorough handling of missing data.

\section{Material and methods}

\section{Material}

Central Denmark Region is one of five administrative units in Denmark with 700,000 inhabitants between 25 and 67 years of age. ${ }^{21}$ All patients from this region who are referred acutely as well as sub-acutely for PCI are treated in one single unit at Aarhus University Hospital, Skejby. From February 2006 to March 2008, we enrolled all first time PCI-treated patients below 67 years of age. In this period, 3,966 persons were treated with PCI at this hospital. Patients with no record of previous PCI $(n=1,752)$ were recruited continuously from the hospital's administrative system of patients. Information on addresses and vital status were collected from the Danish Central Person Register prior to approaching each patient and 26 patients were excluded because they died within the first 4 weeks after PCI. This resulted in a cohort of 1,726 patients.

One month after the PCI, patients were mailed a questionnaire including questions on self-rated health. In the first questionnaire, patients were also asked to further participate in the long-term follow-up survey. Patients who accepted further follow-up were mailed repetitive questionnaires for at least 3 years. These follow-up questionnaires included a selfrated health short form 12-item survey (SF-12) ${ }^{22}$ and cardiac symptoms questionaire (Seattle Angina Questionnaire). ${ }^{23}$ In order to reduce the number of missing questionnaires at each point of time in the analyses, we developed an algorithm that selected questionnaires for each patient with the best fit with respect to eight fixed time points at 1, 3, 6, 12, 18, 24, 30 , and 36 months. The first questionnaire was returned by 1,294 patients $(81.6 \%)$ and the following questionnaires were returned by 839 to 1,104 patients. (Table 1).

Table I Response patterns and attrition in a cohort of patients treated with $\mathrm{PCl}$ at Aarhus University Hospital, Skejby ( $\mathrm{N}=\mathrm{I}, 726)$

\begin{tabular}{|c|c|c|c|c|c|c|c|c|}
\hline Description & I mth & 3 mth & $6 \mathrm{mth}$ & 12 mth & $18 \mathrm{mth}$ & 24 mth & 30 mth & $36 \mathrm{mth}$ \\
\hline Overall mortality (n) & NA & 5 & 5 & 9 & 15 & 14 & 14 & 12 \\
\hline Alive in current round (n) & $\mathrm{I}, 726^{\mathrm{a}}$ & $|, 72|$ & 1,716 & $\mathrm{I}, 707$ & 1,692 & 1,678 & 1,664 & 1,652 \\
\hline From previous round $(n)$ & NA & 1,323 & 1,112 & $\mathrm{I}, 057$ & 1,012 & 980 & 954 & 892 \\
\hline Attrition $(n)^{b}$ & 262 & 211 & 55 & 45 & 32 & 26 & 62 & 39 \\
\hline Available for next round (n) & 1,323 & 1,112 & $\mathrm{I}, 057$ & 1,012 & 980 & 954 & 892 & NA \\
\hline Intermittent missing questionnaire $(n)$ & $29 c$ & 8 & 31 & 53 & 64 & 73 & 53 & NA \\
\hline Returned questionnaires ( $\mathrm{n}$ ) & $\mathrm{I}, 294$ & $\mathrm{I}, 104$ & 1,026 & 959 & 916 & 881 & 839 & $853^{c}$ \\
\hline Response rate according to previous round (\%) & NA & $83.4 \%$ & $92.2 \%$ & $90.7 \%$ & $90.5 \%$ & $89.9 \%$ & $87.9 \%$ & $95.6 \%$ \\
\hline \multicolumn{9}{|l|}{ Questionnaire specific response } \\
\hline \multicolumn{9}{|l|}{ SF-12 PCS/MCS } \\
\hline Complete (n) & $\mathrm{I}, \mathrm{I} 44$ & 979 & 945 & 899 & 858 & 827 & 783 & $780^{c}$ \\
\hline Incomplete (n) & 150 & 125 & 81 & 60 & 58 & 54 & 56 & 73 \\
\hline \multicolumn{9}{|l|}{ Seattle Angina Questionnaire (frequency dimension) } \\
\hline Complete (n) & NA & I,046 & $\mathrm{I}, 007$ & 888 & 798 & 728 & 682 & $73 I^{c}$ \\
\hline Incomplete (n) & NA & 58 & 19 & 71 & 118 & 153 & 157 & 122 \\
\hline \multicolumn{9}{|c|}{ Seattle Angina Questionnaire (stability dimension) } \\
\hline Complete (n) & NA & 1,056 & 1,015 & 891 & 805 & 738 & 690 & $736^{c}$ \\
\hline Incomplete (n) & NA & 48 & II & 68 & III & 143 & 149 & 117 \\
\hline
\end{tabular}

Notes: ${ }^{\mathrm{a}}$ | $4 \mathrm{I}$ patients had hidden addresses and were not sent questionnaires; ${ }^{\mathrm{b}}$ dead or non-respondents after two reminders; ${ }^{\mathrm{c} i n t e r m i t t e n t}$ missing questionnaire in first round occurred when the first questionnaire was delayed from the patient to the second time point 3 months after PCl. The following intermittent missing questionnaires occurred because all patients who stopped answering during follow-up without any known reason were mailed a final questionnaire. This resulted in an increase in returned questionnaires in the final round.

Abbreviations: PCl, percutaneous coronary intervention; mth, months; NA, not applicable; SF-12, short form I2-item survey; MCS, mental component summary; PCS, physical component summary. 
The SF-12 is a generic health survey consisting of 12 questions that correspond to eight subscales and two summary scores. ${ }^{24}$ The summary scores include a physical component summary (PCS) and a mental component summary (MCS), each graded from 0 to 100 , with higher scores indicating a better health outcome. In this study we present results using the MCS and PCS.

From the questionnaire at 3 months we used information on educational level, categorized as low (less than 10 years' education), medium (11-14 years of education), and high (more than 15 years of education) from the International Standard Classification of Education, ${ }^{25}$ and leisure time physical activity was categorized into four categories: less than 2 hours per week, 2-4 hours per week, more than 4 hours per week, or, more than 4 hours per week and heavy.

Supplementary to the questionnaires, we had access to different sources of register-based data. In Denmark, every resident is provided with a permanent and unique civil registration number that enables individual-level linkage between registries. Sex and age were obtained from the registration number. Information on date of death was collected from the Danish Civil Registration System. Data on public transfer incomes on a weekly basis was provided by the Danish Register for Evaluation of Marginalization, ${ }^{26}$ while information on body mass index, smoking, indication for the PCI (acute or elective), and the left ventricular ejection fraction (LVEF) was provided by the West Denmark Heart Registry. ${ }^{27}$ Data on comorbidity were obtained from the Danish National Patient Registry and recoded to Charlson Index. ${ }^{28}$ Charlson Index was further categorized into $0,1-2$, and more than 3 diseases.

\section{Methods}

We used multiple imputation to handle missing data in the study. The multiple imputation was based on data from the questionnaires as well as on register-based information and took the individual time course into account. We imputed all types of missing data, whether it was a single observation or a whole series due to non-participation or drop out. However, data that were not available because a person died were not considered missing data in this paper and thus not imputed. The results were supplemented with three sensitivity scenarios in which missing measurements were assumed to represent subjects with lower health than estimated with the imputation models. The details of multiple imputation and sensitivity analyses are given in the related methodology paper. ${ }^{29}$

The MCS and PCS were analyzed by linear mixed models assuming random person levels and that the within-person correlation between two scores decreased exponentially with the number of months between the questionnaires. We first present the mean MCS and PCS scores along with estimates of increases per year. Then we present analyses with focus on sex, age, LVEF, indication for the PCI (acute/elective), and educational level, which have previously been found to be associated with differences in health in cross sectional studies. We dichotomized educational level with low in one group, and intermediate and high in the other group. Age and LVEF was analyzed continuously. For each factor in focus, we estimated the adjusted difference between the levels at each time point, the yearly change in the difference, and the difference assuming that it was constant over time.

We defined a strong decline in health post hoc as an average decrease of more than four points per year in the given SF-12 component score (the four points per year is roughly identical with the tenth percentile). The association between a strong decline and the factors listed above was estimated by adjusted odds ratios by ordinary logistic regression.

The same sets of potential confounders selected a priori were applied in both types of analyses. We adjusted for age, sex, and comorbidity in all analyses. Furthermore, we adjusted analyses of sex for indication, LVEF, and educational level; indication for educational level and lifestyle factors (smoking, physical activity, and body mass index); age for LVEF, educational level, and lifestyle factors; LVEF for indication; and finally educational level for LVEF and lifestyle factors.

Data management, multiple imputation, and statistical analyses were made using Stata 12.1 (StataCorp LP, College Station, TX, USA). Estimates are reported with $95 \%$ confidence intervals in brackets and $P$-values below 5\% were considered statistically significant.

\section{Ethics statement}

The Danish Data Protection Agency approved the study, Ref \# 2007-41-0991.

According to Danish law, approval by the Ethics Committee and written informed consent is not required in questionnaire-based and register-based projects.

Additional information is available at The National Committee on Health Research Ethics' webpage in the "Act on Research Ethics Review of Health Research Projects" § 14,2. available from: http://www.cvk.sum.dk/ English/actonabiomedicalresearch.aspx.

\section{Results}

Almost $80 \%$ of the patients were men, and $32 \%$ were treated acutely (Table 2). The baseline characteristics were much the 
Table 2 Patient characteristics at PCl, total and stratified on sex and indication

\begin{tabular}{|c|c|c|c|c|c|c|c|c|c|c|}
\hline & \multicolumn{2}{|c|}{ All patients } & \multicolumn{4}{|l|}{ Sex } & \multicolumn{4}{|c|}{ Indication } \\
\hline & \multirow[t]{2}{*}{$\mathbf{N}$} & \multirow[t]{2}{*}{ (\%) } & \multicolumn{2}{|l|}{ Male } & \multicolumn{2}{|c|}{ Female } & \multicolumn{2}{|c|}{ Acute } & \multicolumn{2}{|c|}{ Other } \\
\hline & & & $\mathbf{N}$ & (\%) & $\mathbf{N}$ & (\%) & $\mathbf{N}$ & (\%) & $\mathbf{N}$ & $(\%)$ \\
\hline Total & 1,726 & $(100)$ & 1,360 & $(100)$ & 366 & $(100)$ & 557 & $(100)$ & 1,169 & $(100)$ \\
\hline \multicolumn{11}{|l|}{ Sex } \\
\hline Male & 1,360 & (79) & 1,360 & $(100)$ & - & - & 446 & $(80)$ & 914 & (78) \\
\hline Female & 366 & $(21)$ & - & - & 366 & $(100)$ & III & (20) & 255 & (22) \\
\hline \multicolumn{11}{|l|}{ Indication } \\
\hline Acute & 557 & $(32)$ & 446 & (33) & 111 & $(30)$ & 557 & $(100)$ & - & - \\
\hline Elective & 1,169 & $(68)$ & 914 & $(67)$ & 255 & $(70)$ & - & - & 1,169 & $(100)$ \\
\hline \multicolumn{11}{|l|}{ Age } \\
\hline$\leq 44$ y & 168 & $(10)$ & 117 & (9) & 51 & $(14)$ & 82 & (I5) & 86 & (7) \\
\hline $45-54 y$ & 476 & $(28)$ & 388 & (29) & 88 & (24) & 162 & (29) & 314 & $(27)$ \\
\hline $55-59 y$ & 393 & $(23)$ & 318 & (23) & 75 & $(20)$ & 120 & $(22)$ & 273 & $(23)$ \\
\hline $60-67 y$ & 689 & $(40)$ & 537 & (39) & 152 & $(42)$ & 193 & (35) & 496 & $(42)$ \\
\hline \multicolumn{11}{|l|}{ LVEF } \\
\hline$\leq 34 \%$ & 89 & (5) & 69 & (5) & 20 & (5) & 35 & (6) & 54 & (5) \\
\hline $35 \%-54 \%$ & 612 & $(35)$ & 505 & (37) & 107 & (29) & 283 & $(5 I)$ & 329 & $(28)$ \\
\hline $55+\%$ & 895 & $(52)$ & 688 & $(5 \mathrm{I})$ & 207 & $(57)$ & 185 & (33) & 710 & $(6 I)$ \\
\hline Missing & 130 & (8) & 98 & (7) & 32 & (9) & 54 & $(10)$ & 76 & (7) \\
\hline \multicolumn{11}{|l|}{ Educational level } \\
\hline Low $(<\mathrm{II}$ y) & 253 & $(15)$ & 186 & $(14)$ & 67 & $(18)$ & 79 & $(14)$ & 174 & $(15)$ \\
\hline Intermediate (I I-I4 y) & 742 & $(43)$ & 606 & $(45)$ & 136 & (37) & 237 & $(43)$ & 505 & $(43)$ \\
\hline High $(15+y)$ & 561 & (33) & 459 & (34) & 102 & $(28)$ & 197 & (35) & 364 & (3I) \\
\hline Missing & 170 & $(10)$ & 109 & (8) & 61 & $(17)$ & 44 & $(8)$ & 126 & (II) \\
\hline \multicolumn{11}{|l|}{ Comorbidity } \\
\hline Charlson Index 0 & 1,010 & (59) & 802 & (59) & 208 & (57) & 410 & $(74)$ & 600 & $(5 \mathrm{I})$ \\
\hline Charlson Index I & 393 & $(23)$ & 312 & (23) & 81 & (22) & 80 & (14) & 313 & $(27)$ \\
\hline Charlson Index 2+ & 323 & (19) & 246 & $(18)$ & 77 & $(21)$ & 67 & (12) & 256 & (22) \\
\hline \multicolumn{11}{|l|}{ Smoking } \\
\hline Never & 330 & $(19)$ & 262 & (19) & 68 & (19) & 84 & (15) & 246 & $(2 I)$ \\
\hline Current & 763 & (44) & 583 & $(43)$ & 180 & (49) & 337 & (6I) & 426 & (36) \\
\hline Previous & 597 & (35) & 490 & (36) & 107 & (29) & 124 & $(22)$ & 473 & $(40)$ \\
\hline Missing & 36 & $(2)$ & 25 & (2) & 11 & (3) & 12 & (2) & 24 & $(2)$ \\
\hline \multicolumn{11}{|l|}{ BMI } \\
\hline$\leq 24.9 \mathrm{~kg} / \mathrm{m}^{2}$ & 485 & $(28)$ & 328 & $(24)$ & 157 & $(43)$ & 166 & $(30)$ & 319 & $(27)$ \\
\hline $25-29.9 \mathrm{~kg} / \mathrm{m}^{2}$ & 774 & $(45)$ & 666 & (49) & 108 & (30) & 261 & $(47)$ & 513 & (44) \\
\hline $30+\mathrm{kg} / \mathrm{m}^{2}$ & 425 & $(25)$ & 332 & (24) & 93 & $(25)$ & 109 & $(20)$ & 316 & $(27)$ \\
\hline Missing & 42 & $(2)$ & 34 & (3) & 8 & $(2)$ & 21 & (4) & 21 & $(2)$ \\
\hline \multicolumn{11}{|c|}{ Physical activity (at 3 months) } \\
\hline$<2 \mathrm{~h} / \mathrm{wk}$ & 96 & (6) & 69 & (5) & 27 & (7) & 20 & $(4)$ & 76 & (7) \\
\hline $2-4 \mathrm{~h} / \mathrm{wk}$ & 402 & $(23)$ & 293 & $(22)$ & 109 & (30) & 125 & $(22)$ & 277 & (24) \\
\hline$>4 \mathrm{~h} / \mathrm{wk}$, light & 480 & $(28)$ & 406 & (30) & 74 & (20) & 157 & (28) & 323 & (28) \\
\hline$>4 \mathrm{~h} / \mathrm{wk}$, heavy & 82 & (5) & 77 & (6) & 5 & (I) & 21 & $(4)$ & 61 & (5) \\
\hline Missing & 666 & (39) & 515 & (38) & $15 \mid$ & $(4 I)$ & 234 & $(42)$ & 432 & (37) \\
\hline
\end{tabular}

Abbreviations: $\mathrm{PCl}$, percutaneous coronary intervention; LVEF, left ventricular ejection fraction; $y$, years; BMI, body mass index; h/wk, hours per week.

same for men and women, except that women were less often overweight or obese. Patients treated acutely were younger, had a higher LVEF, were more often smokers, and less often had comorbidity (Table 2).

Mental health improved slightly during follow-up, with an increase of $0.74(0.50 ; 0.98)$ points per year, with most of the improvements in the first 6 months after PCI. Physical health did not improve; the estimated increase per year was $0.09(-0.14 ; 0.32)$ (Figure 1 and Table 3 , first column). Note that we plotted both curves in the same diagram on the same scale, but the two scores are different domains, and the absolute levels are consequently not comparable.

The adjusted analysis of MCS scores showed that women rated their mental health lower than men (Figure 2, upper part, Table 3). The sex differences in mental health were not stable over time; they were largest in the beginning, but 


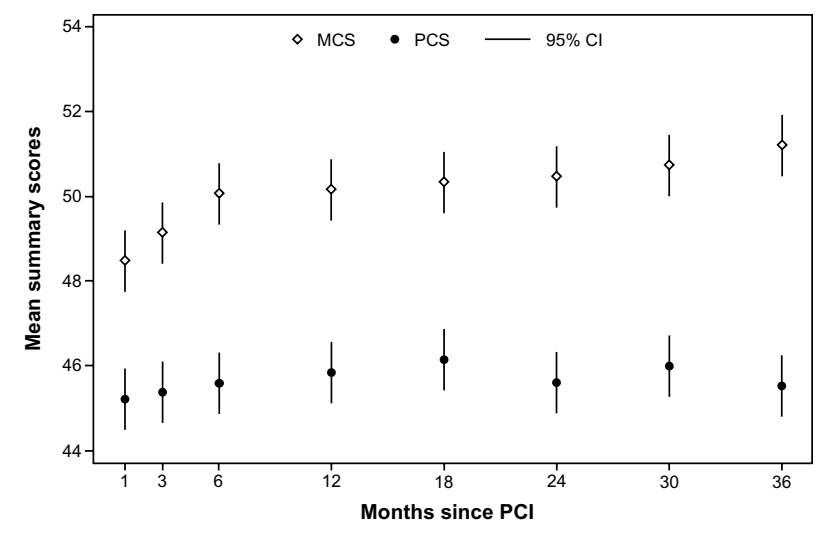

Figure I Course of mental component summary and physical component summary following percutaneous coronary intervention.

Abbreviations: MCS, mental component summary; PCS, physical component summary; $\mathrm{Cl}$, confidence interval; $\mathrm{PCl}$, percutaneous coronary intervention.

diminished over time $(P=0.01)$. There were no differences in mental health between patients treated acutely compared to other indications. Younger patients rated their mental health lower than older patients. We found no difference related to LVEF. Patients with low educational level rated their mental health at the same levels as patients with intermediate or high education.

In the adjusted analyses of physical health, women rated their health lower than men (Figure 2, lower part, Table 3). We also found that patients treated acutely rated their physical health higher than electively treated patients, though not significantly at all time points, except in the first measurement 4 weeks after the PCI. The differences in physical health between acute indication and elective indication were not stable over time $(P=0.01)$. In contrast to the analyses of mental health, we found no age-related difference related to the rating of physical health. High LVEF had a minor positive influence in the beginning of the study, but this diminished over time. Patients with a low educational level rated their physical health worse than patients with intermediate or high education.

Considering marked decreases in health ( $>$ four points/ year), young age seemed to be associated with decreases in both MCS and PCS, but only significantly in MCS. A nonacute indication for PCI was associated with a decrease in MCS, and female sex was associated with a decrease in PCS; however, none of these results were statistically significant (Table 4).

\section{Sensitivity analyses}

When we applied scenarios in which patients for whom data were missing had worse scores than what we could derive from multiple imputation models, we found, as expected, that the sensitivity analyses decreased the population level of both MCS and PCS. This diminished the increase over time in MCS and resulted in a possible decline over time of PCS. In the analyses of the five factors presented in Table 3 , the following deviations were observed following sensitivity analyses: differences by sex, indication, and LVEF increased for both MCS and PCS, while differences by educational level decreased. Differences due to age were in opposite directions as differences in PCS decreased and differences in MCS increased. In general, changes were in the order of a half point, except regarding educational level that changed around one point. The sensitivity analysis did not affect the estimates following the analyses of the strong decline presented in Table 4 (data not shown).

The results of the sensitivity analyses showed that, given unobserved measurements represented lower mental and physical health than estimated by the imputation model, mean scores, and subsequently the changes in scores over time at the population level, would be affected, while the group difference estimates were less affected.

\section{Discussion}

In a large, geographically well-defined population of younger patients treated with PCI, mental health improved during follow-up, with the largest improvements during the first 6 months following PCI. Physical health did not improve. The pronounced sex differences in mental health diminished over time, while the sex differences in physical health ratings were stable. In patients less than 55 years of age mental health but not physical health was affected, in comparison to the older patients. Differences related to indication, LVEF, and educational level were negligible. To our knowledge, this study is the largest study with the greatest number of measurement points to date. Furthermore, this is the first study using a complete, unselected cohort of PCI patients with patient-reported outcomes. A previous study used multiple imputation to impute intermittent missing data among respondents in a similar study design, but this cohort employed a selected population and non-respondents were not imputed. They experienced a higher dropout rate $(\sim 50 \%$ of the original participants at 36 months) and did not use register-based information in their imputation. ${ }^{20}$

This study was based on a cohort of younger PCI patients with complete information from a number of registers. The initial response rate was relatively high, and $60 \%$ of the initial respondents participated in all 3 years of follow-up. However, the patients who were non-respondents and those who stopped during follow-up differed from the whole-course 
Table 3 Means and adjusted ${ }^{\mathrm{a}}$ mean differences in self-reported mental health and physical health with $95 \%$ confidence intervals

\begin{tabular}{|c|c|c|c|c|c|c|}
\hline & Mean & Sex & $\begin{array}{l}\text { Indication } \\
\text { of } \mathrm{PCl}\end{array}$ & $\begin{array}{l}\text { Educational } \\
\text { level }\end{array}$ & Age & LVEF \\
\hline & & $\begin{array}{l}\text { Male vs } \\
\text { female }\end{array}$ & $\begin{array}{l}\text { Acute vs } \\
\text { other }\end{array}$ & $\begin{array}{l}\text { Medium/ } \\
\text { high vs low }\end{array}$ & Per 10 years & Per $10 \%$ \\
\hline \multicolumn{7}{|l|}{ MCS } \\
\hline \multicolumn{7}{|l|}{ Months since $\mathrm{PCl}$} \\
\hline I & $48.5(47.9 ; 49.1)$ & $4.8(6.3 ; 3.3)$ & $0.3(-1.0 ; 1.6)$ & $0.8(-0.6 ; 2.3)$ & $2.1(1.3 ; 2.9)$ & $0.3(-0.3 ; 0.8)$ \\
\hline 3 & $49.2(48.6 ; 49.8)$ & $4.6(6.1 ; 3.1)$ & $0.3(-1.1 ; 1.6)$ & $0.5(-1.0 ; 1.9)$ & $2.9(2.0 ; 3.8)$ & $-0.3(-0.9 ; 0.3)$ \\
\hline 6 & $50.1(49.5 ; 50.7)$ & $3.1(4.7 ; 1.6)$ & 0.3 (-I.I; I.7) & $0.5(-1.0 ; 2.0)$ & $3.3(2.4 ; 4.2)$ & $-0.3(-1.0 ; 0.3)$ \\
\hline 12 & $50.2(49.6 ; 50.8)$ & $3.3(4.7 ; 1.8)$ & $0.5(-0.8 ; 1.8)$ & $0.1(-1.4 ; 1.5)$ & $3.2(2.3 ; 4.2)$ & $0.0(-0.6 ; 0.7)$ \\
\hline 18 & $50.3(49.7 ; 50.9)$ & $2.6(4.1 ; 1.1)$ & $0.8(-0.6 ; 2.2)$ & $0.3(-1.2 ; 1.8)$ & $3.6(2.7 ; 4.4)$ & $-0.1(-0.7 ; 0.5)$ \\
\hline 24 & $50.5(49.8 ; 5 \mid .2)$ & $1.8(3.4 ; 0.3)$ & $0.9(-0.4 ; 2.2)$ & $0.4(-1.2 ; 1.9)$ & $3.1(2.2 ; 4.0)$ & $0.1(-0.5 ; 0.8)$ \\
\hline 30 & $50.7(50.0 ; 51.4)$ & $2.7(4.2 ; 1.1)$ & $1.5(0.1 ; 2.9)$ & $0.1(-1.4 ; 1.6)$ & $3.3(2.3 ; 4.2)$ & $-0.2(-0.8 ; 0.5)$ \\
\hline 36 & $51.2(50.5 ; 51.9)$ & $1.5(3.2 ;-0.2)$ & $1.5(0.0 ; 3.0)$ & $0.4(-I . I ; 2.0)$ & $3.3(2.4 ; 4.3)$ & $0.1(-0.6 ; 0.8)$ \\
\hline Constant since $\mathrm{PCl}$ ? & $P<0.01$ & $P=0.01$ & $P=0.75$ & $P=0.98$ & $P=0.10$ & $P=0.38$ \\
\hline $\begin{array}{l}\text { If assumed constant } \\
\text { since } \mathrm{PCl}\end{array}$ & $50.2(49.7 ; 50.6)$ & $2.9(3.9 ; 1.8)$ & $0.8(-0.2 ; 1.8)$ & $0.4(-0.7 ;$ I.5) & $3.1(2.5 ; 3.7)$ & $0.0(-0.5 ; 0.4)$ \\
\hline Increase per year & $0.74(0.50 ; 0.98)$ & $1.0(1.6 ; 0.4)$ & $-0.5(-0.9 ; 0.0)$ & $0.1(-0.4 ; 0.6)$ & $0.3(-0.1 ; 0.6)$ & $0.0(-0.2 ; 0.3)$ \\
\hline \multicolumn{7}{|l|}{ PCS } \\
\hline \multicolumn{7}{|l|}{ Months since $\mathrm{PCl}$} \\
\hline I & $45.2(44.6 ; 45.8)$ & $3.6(5.1 ; 2.2)$ & $0.2(-I . I ; I .5)$ & $2.0(0.5 ; 3.5)$ & $-0.1(-0.9 ; 0.7)$ & I.3 (0.7; I.9) \\
\hline 3 & $45.4(44.8 ; 46.0)$ & $4.1(5.5 ; 2.7)$ & $1.7(0.3 ; 3.2)$ & I.8 $(0.3 ; 3.3)$ & $-0.4(-1.2 ; 0.5)$ & $1.4(0.7 ; 2.0)$ \\
\hline 6 & $45.6(44.9 ; 46.2)$ & $4.5(6.1 ; 2.9)$ & $2.1(0.7 ; 3.6)$ & I.5 (-0.1; 3.0) & $0.2(-0.7 ;$ I.I $)$ & $0.9(0.2 ; 1.5)$ \\
\hline 12 & $45.8(45.2 ; 46.5)$ & $4.9(6.5 ; 3.3)$ & $1.9(0.4 ; 3.4)$ & $1.9(0.3 ; 3.5)$ & $0.2(-0.7 ;$ I.I $)$ & $0.9(0.3 ; 1.5)$ \\
\hline 18 & $46.1(45.5 ; 46.8)$ & $4.4(5.9 ; 2.8)$ & $2.3(0.8 ; 3.7)$ & $1.5(-0.1 ; 3.1)$ & $-0.1(-1.1 ; 0.8)$ & $0.7(0.0 ; 1.3)$ \\
\hline 24 & $45.6(44.9 ; 46.2)$ & $5.4(7.1 ; 3.8)$ & I.3 $(-0.2 ; 2.8)$ & I.7 (0.1; 3.3) & $0.1(-0.9 ; 1.0)$ & $0.9(0.2 ; 1.5)$ \\
\hline 30 & $45.9(45.3 ; 46.6)$ & $5.4(7.1 ; 3.8)$ & $1.5(0.0 ; 3.0)$ & $1.9(0.3 ; 3.5)$ & $0.3(-0.7 ; 1.2)$ & $0.9(0.2 ; 1.6)$ \\
\hline 36 & $45.5(44.8 ; 46.2)$ & $4.6(6.2 ; 2.9)$ & $1.6(0.2 ; 3.1)$ & I.8 (0.1; 3.4) & $0.0(-1.0 ; 1.0)$ & $1.0(0.3 ; 1.7)$ \\
\hline Constant since $\mathrm{PCl}$ ? & $P=0.13$ & $P=0.39$ & $P=0.01$ & $P=0.98$ & $P=0.79$ & $P=0.4 \mathrm{I}$ \\
\hline $\begin{array}{l}\text { If assumed constant } \\
\text { since } \mathrm{PCl}\end{array}$ & $45.6(45.1 ; 46.2)$ & $-4.6(-5.9 ;-3.4)$ & $1.5(0.4 ; 2.7)$ & I.8 $(0.5 ; 3.1)$ & $0.0(-0.7 ; 0.7)$ & $1.0(0.4 ; 1.5)$ \\
\hline Increase per year & $0.09(-0.14 ; 0.32)$ & $0.4(-0.2 ; 0.9)$ & $-0.2(-0.7 ; 0.2)$ & $0.0(-0.5 ; 0.5)$ & $0.1(-0.3 ; 0.4)$ & $-0.1(-0.3 ; 0.1)$ \\
\hline
\end{tabular}

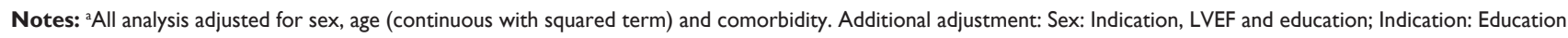
and lifestyle (smoking, physical activity and BMI); Education: LVEF and lifestyle; Age: LVEF, education and lifestyle; LVEF: Indication.

Abbreviations: vs, versus; MCS, mental component summary; PCS, physical component summary; PCl, percutaneous coronary intervention; LVEF, left ventricular ejection fraction; BMI, body mass index.

respondents in a number of aspects, so we used multiple imputation in order to diminish selection bias. We refer to the methodology paper $^{29}$ for further details regarding the discussion of missing data in the cohort.

Patients were first included in the study after the PCI, and thus a measurement before the procedure was not available. In some previous studies of elective PCI patients a measurement preceding the PCI was included, ${ }^{10,16-20,30}$ but whether or not this reflects the patient's habitual level of health is unknown.

The algorithm that forced each questionnaire into the specified time pattern was a pragmatic choice in order to present data in an orderly way. However, by using the date of death, we ensured that no measurement could be defined after the date of death for any individual.

De Smedt et al found SF-12 valid and reliable in a large population of European coronary heart disease patients. ${ }^{31}$
Since SF-12 is shorter than SF-36, it minimizes the respondent burden, but may not distinguish between different domains in patients following myocardial infarction. ${ }^{18}$ However, Dempster and Donnelly found SF-12 to be preferable to SF-36 in ischemic heart disease patients. ${ }^{32}$

In the original manual of SF-36, Ware suggested that differences larger than five points were clinically and socially relevant, ${ }^{33}$ and comparable to a moderate effect size according to Cohen's rule of thumb. Most of the mean changes over time in our study were much smaller, and the adjusted differences only reached five points in the analyses of sex (MCS and PCS) and age (MCS). Other differences were small.

Distinguishing between patients who had a decline of more than four points per year compared to patients with an increase or less decline gave only limited information about what would characterize patients with a strong decline in 


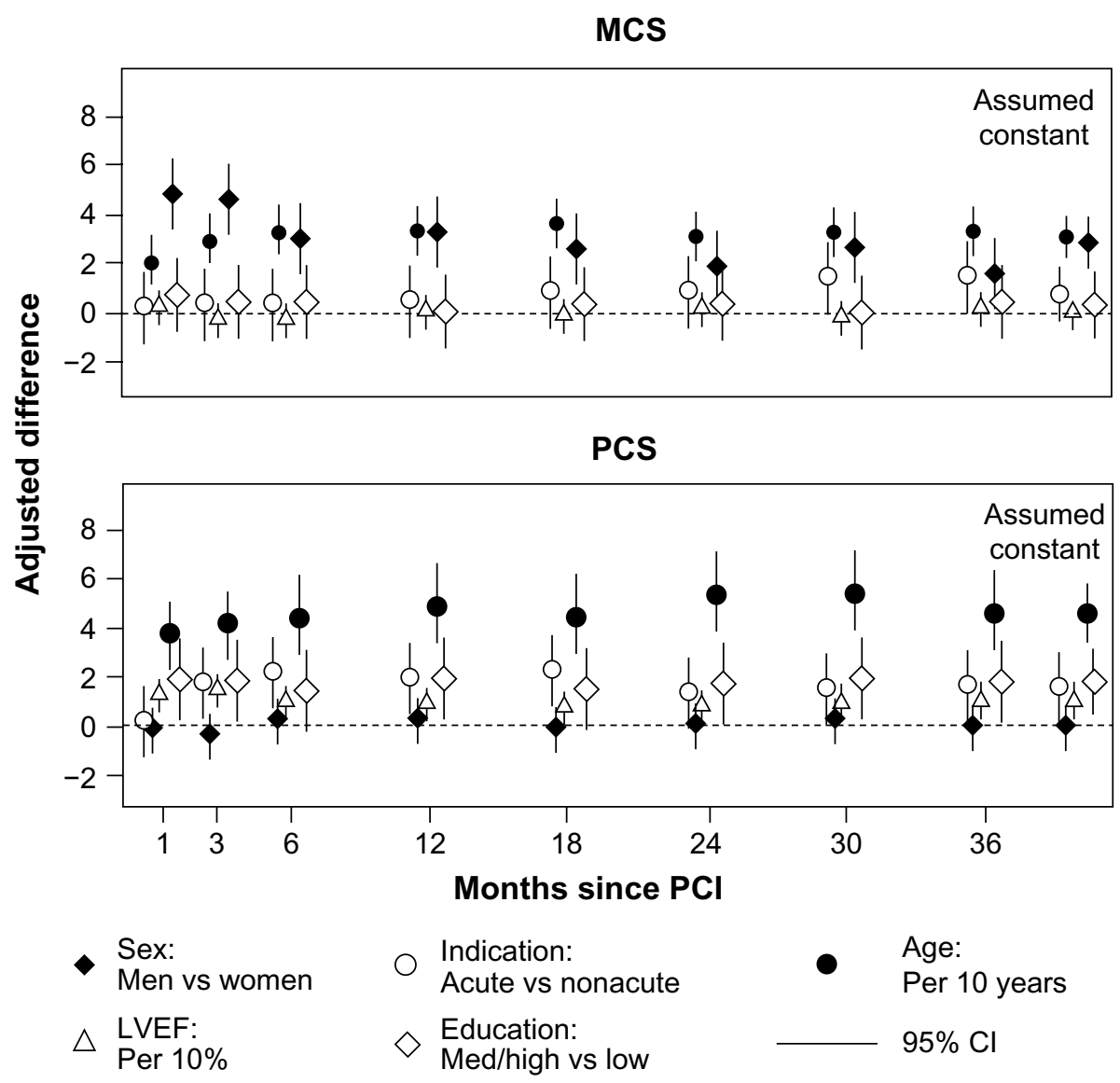

Figure 2 Adjusted differences in mental component summary and physical component summary between the five factors in focus: indication, age, left ventricular ejection fraction, sex, and educational level at 8 points of time following $\mathrm{PCl}$.

Abbreviations: MCS, mental component summary; PCS, physical component summary; PCl, percutaneous coronary intervention; Cl, confidence interval; LVEF, left ventricular ejection fraction; Med, medium; vs, versus.

self-rated health. This may relate to the fact that we used data on prevalent comorbidity only and not incident comorbidity and new cardiac events during follow-up, that are likely to be related to decline.

In this paper we report only the generic measure SF-12, and not the disease specific measure Seattle Angina Questionnaire. A large majority of the patients reported no symptoms on the frequency and stability scales of the Seattle Angina Questionnaire, and thus it was not possible to detect changes and report the course of symptoms as intended.
Post-procedure treatment such as compliance to medicine and rehabilitation may be important confounders related to self-rated health. These were unmeasured in this study, however, we did try to obtain information about participation in rehabilitation from self-report in one of the questionnaires, but the quality of these data were not high and a large proportion of patients had these items missing, and we did not have sufficient data to impute this.

Most previous longitudinal studies that report the course of mean scores of self-reported health in heart patients found

Table 4 Association between patients' characteristics and a decrease in SF-12 component summary score larger than four points per year (adjusted ${ }^{\mathrm{a}}$ odds ratios with $95 \%$ confidence intervals)

\begin{tabular}{|c|c|c|c|c|c|}
\hline & Sex & Indication of $\mathrm{PCl}$ & Educational level & Age & LVEF \\
\hline & $\overline{\text { Male vs female }}$ & Acute vs other & $\overline{\text { Medium/high vs low }}$ & Per 10 years & Per $10 \%$ \\
\hline MCS & I.38 $(0.72 ; 2.64)$ & $0.70(0.40 ; 1.25)$ & $\mathrm{I} .03(0.60 ; \mathrm{I} .79)$ & $0.7 I(0.54 ; 0.95)$ & $0.93(0.74 ;$ I. I 7$)$ \\
\hline PCS & $0.69(0.43 ; 1.11)$ & $0.95(0.57 ; 1.59)$ & $1.09(0.61 ; 1.96)$ & $0.74(0.56 ; 1.00)$ & $\mathrm{I} .00(0.8 \mathrm{I} ; \mathrm{I} .25)$ \\
\hline
\end{tabular}

Notes: ${ }^{a}$ All analysis adjusted for sex, age (continuous with squared term) and comorbidity. Additional adjustment: Sex: Indication, LVEF and education; Indication: Education and lifestyle (smoking, physical activity and BMI); Education: LVEF and lifestyle; Age: LVEF, education and lifestyle; LVEF: Indication.

Abbreviations: SF-12, short form I2-item survey; MCS, mental component summary; PCS, physical component summary; PCI, percutaneous coronary intervention; LVEF, left ventricular ejection fraction; BMI, body mass index; vs, versus. 
improvements in the first 3-6 months, after which a steady level was reached. In general, improvements in physical health were larger than those in mental health. ${ }^{17-20}$ However, the improvements in the component summaries are in general small, as in our current study. Results based on the imputation model seem to be robust to modest departures from the assumptions of missing at random behind the imputation, based on sensitivity analyses.

Other studies report score changes in different ways. Rubenach et al measured health-related quality of life in 65 patients following myocardial infarction, with five measurement points over 24 weeks. They found that patients reported poorer physical and mental health during follow-up than at baseline. Only patients who completed the entire study were included in the analysis, but characteristics of non-participants and patients lost to follow-up were reported, and weighting was used in the analysis. ${ }^{18}$ Skodova et al supplemented with a division into subgroups of patients who improved, were unchanged, or declined. This division was based on effect sizes; changes $>1.96$ standard error of the mean defined change. They found that approximately half of the patients were stable over the first year, $40 \%$ improved, but $10 \%$ experienced a worsening of health, but the sample size of PCI patients was limited $(\mathrm{N}=37) .{ }^{11}$ Our study showed that $10 \%$ of the patients experienced a decline equivalent to four points per year or more. We did not find that any of the patient characteristics related to decline in health.

Sex differences in self-reported health are well-known from other studies. ${ }^{12,13,34}$ Mortensen et al found that women had lower scores in both the MCS and the PCS after both 1 month and 12 months, and they had a larger increase in scores over time. ${ }^{12}$ This compares well with our findings in regard to the MCS, but in our study the sex difference in PCS scores was stable over the follow-up period. Pedersen et al found that women rated their health lower in all eight subscales of SF-36, 6, and 12 months after PCI, but they did not find any interaction with sex over time. ${ }^{13}$ This was in contrast to our findings, possibly because of the longer follow-up time and the multiple measure points in our study. Sex differences in prognosis in terms of mortality have been reported to disappear after adjustment for age and comorbidity, ${ }^{34-36}$ but these adjustments (along with adjustment for educational level, LVEF, and indication) could not explain the differences in this study. The sex differences in MCS scores found in our study were larger than in the general Danish population aged 55-64, where the difference is $\sim 1 .{ }^{37}$ Especially at the beginning of the study, MCS scores for women were lower than for men, but towards the end of the study the difference came closer to the sex difference in the general population. The sex difference in PCS scores was larger than in the general Danish population aged 55-64, where the difference is $\sim 2.5,{ }^{37}$ even after adjustment for possible confounding factors such as age, indication, LVEF, educational level, and comorbidity. Previously, a sex difference in difficulties regarding return to work was demonstrated in our cohort. ${ }^{5}$

In our study younger patients reported lower scores in MCS, but not in PCS, compared with older patients, even after adjustment for sex, LVEF, educational level, comorbidity, and lifestyle. In the general population, PCS scores decrease with age, while MCS scores are more constant. ${ }^{37}$

Previous studies have found differences related to socio-economic status in health-related quality of life following PCI. ${ }^{30,38}$ We could only reproduce these findings in the PCS, possibly because of different definitions of socioeconomic status or other methodological differences.

This study covers all incident PCI patients, under the age of 67 years, originating from a well-defined population in Denmark. To our knowledge this is the largest study with the most measurement points, and moreover the first study to include a complete unselected cohort achieved with the use of multiple imputation. The findings have high external validity in relation to countries with similar patient groups referred for PCI.

\section{Conclusion}

In a complete population-based cohort of PCI patients with multiple measurements, we found improvements in mental, but not physical health over time. Demographic differences in health were larger than were disease-related differences, thus, obtaining patient-reported health may add valuable information in clinical practice.

\section{Disclosure}

The authors report no conflicts of interest in this work.

\section{References}

1. The Danish Heart Foundation, National Institute of Public Health. Hjertekarsygdomme i Danmark - forekomst og udvikling 2000-2009. [Cardiovascular Disease in Denmark: Occurrence and Development 2000-2009]. Report, University of Southern Denmark, Copenhagen, Denmark 2011. Danish.

2. Mackay J, Mensah GA. The Atlas of Heart Disease and Stroke. Geneva: World Health Organization; 2004.

3. Rumsfeld JS. Health status and clinical practice: when will they meet? Circulation. 2002;106(1):5-7.

4. Valderas JM, Kotzeva A, Espallargues M, et al. The impact of measuring patient-reported outcomes in clinical practice: a systematic review of the literature. Qual Life Res. 2008;17(2):179-193.

5. Biering K, Nielsen TT, Rasmussen K, Niemann T, Hjollund NH. Return to work after percutaneous coronary intervention: the predictive value of self-reported health compared to clinical measures. PLoS One. 2012;7(11):e49268. 
6. Lenzen MJ, Scholte op Reimer WJ, Pedersen SS, et al. The additional value of patient-reported health status in predicting 1-year mortality after invasive coronary procedures: a report from the Euro Heart Survey on Coronary Revascularisation. Heart. 2007;93(3):339-344.

7. Mejhert M, Kahan T, Persson H, Edner M. Predicting readmissions and cardiovascular events in heart failure patients. Int $J$ Cardiol. 2006;109(1):108-113.

8. Rumsfeld JS, MaWhinney S, McCarthy M Jr, et al. Health-related quality of life as a predictor of mortality following coronary artery bypass graft surgery. Participants of the Department of Veterans Affairs Cooperative Study Group on Processes, Structures, and Outcomes of Care in Cardiac Surgery. JAMA. 1999;281(14):1298-1303.

9. Thombs BD, Ziegelstein RC, Stewart DE, Abbey SE, Parakh K, Grace SL. Physical health status assessed during hospitalization for acute coronary syndrome predicts mortality 12 months later. J Psychosom Res. 2008;65(6):587-593.

10. Hawkes AL, Mortensen OS. Up to one third of individual cardiac patients have a decline in quality of life post-intervention. Scand Cardiovasc J. 2006;40(4):214-218.

11. Skodova Z, van Dijk JP, Nagyova I, et al. Psychosocial predictors of change in quality of life in patients after coronary interventions. Heart Lung. 2011;40(4):331-339.

12. Mortensen OS, Bjorner JB, Newman B, et al. Gender differences in healthrelated quality of life following ST-elevation myocardial infarction: women and men do not benefit from primary percutaneous coronary intervention to the same degree. Eur J Cardiovasc Prev Rehabil. 2007;14(1):37-43.

13. Pedersen SS, Ong AT, Lemos PA, Erdman RA, Serruys PW, van Domburg RT. Risk factors for impaired health status differ in women and men treated with percutaneous coronary intervention in the drugeluting stent era. J Psychosom Res. 2006;61(1):11-17.

14. Schenkeveld L, Pedersen SS, van Nierop JW, et al. Health-related quality of life and long-term mortality in patients treated with percutaneous coronary intervention. Am Heart J. 2010;159(3):471-476.

15. Tofighi S, Ahmad Kiadaliri A, Sadeghifar J, Raadabadi M, Mamikhani J Health-Related Quality of Life among Patients with Coronary Artery Disease: A Post-Treatment Follow-Up Study in Iran. Cardiol Res Pract. 2012;2012:973974.

16. Wong MS, Chair SY. Changes in health-related quality of life following percutaneous coronary intervention: a longitudinal study. Int J Nurs Stud. 2007;44(8):1334-1342.

17. Cohen DJ, Van Hout B, Serruys PW, et al. Quality of life after PCI with drug-eluting stents or coronary-artery bypass surgery. $N$ Engl J Med. 2011;364(11):1016-1026.

18. Rubenach S, Shadbolt B, McCallum J, Nakamura T. Assessing health-related quality of life following myocardial infarction: is the SF-12 useful? J Clin Epidemiol. 2002;55(3):306-309.

19. van Domburg RT, Daemen J, Morice MC, et al. Short- and long-term health related quality-of-life and anginal status of the Arterial Revascularisation Therapies Study part II, ARTS-II; sirolimus-eluting stents for the treatment of patients with multivessel coronary artery disease. EuroIntervention. 2010;5(8):962-967.

20. Weintraub WS, Spertus JA, Kolm P, et al. Effect of PCI on quality of life in patients with stable coronary disease. NEngl J Med. 2008;359(7): 677-687.

21. Danish Health and Medicines Authority [homepage on the Internet]. Treatment in Hospitals. Available from: http://www.ssi.dk/ Sundhedsdataogit.aspx. Accessed September 14, 2014.

Clinical Epidemiology

\section{Publish your work in this journal}

Clinical Epidemiology is an international, peer-reviewed, open access, online journal focusing on disease and drug epidemiology, identification of risk factors and screening procedures to develop optimal preventative initiatives and programs. Specific topics include: diagnosis, prognosis, treatment, screening, prevention, risk factor modification,
22. Ware JE Jr, Sherbourne CD. The MOS 36-item short-form health survey (SF-36). I. Conceptual framework and item selection. Med Care. 1992;30(6):473-483.

23. Spertus JA, Winder JA, Dewhurst TA, et al. Development and evaluation of the Seattle Angina Questionnaire: a new functional status measure for coronary artery disease. J Am Coll Cardiol. 1995;25(2):333-341.

24. Ware J Jr, Kosinski M, Keller SD. A 12-Item Short-Form Health Survey: construction of scales and preliminary tests of reliability and validity. Med Care. 1996;34(3):220-233.

25. United Nations Educational, Scientific and Cultural Organization (UNESCO). International Standard Classification of Education: ISCED 1997. Paris: UNESCO; 1997. Available from: http://www. unesco.org/education/information/nfsunesco/doc/isced_1997.Accessed September 14, 2014.

26. Hjollund NH, Larsen FB, Andersen JH. Register-based follow-up of social benefits and other transfer payments: accuracy and degree of completeness in a Danish interdepartmental administrative database compared with a population-based survey. Scand J Public Health. 2007;35(5):497-502.

27. Schmidt M, Maeng M, Jakobsen CJ, et al. Existing data sources for clinical epidemiology: The Western Denmark Heart Registry. Clin Epidemiol. 2010;2:137-144.

28. Charlson ME, Pompei P, Ales KL, MacKenzie CR. A new method of classifying prognostic comorbidity in longitudinal studies: development and validation. J Chronic Dis. 1987;40(5):373-383.

29. Biering K, Hjollund N, Frydenberg M. Using multiple imputation to deal with missing data and attrition in longitudinal studies with repeated measures of patient-reported outcomes. In press.

30. Skodova Z, Nagyova I, van Dijk JP, et al. Socioeconomic inequalities in quality of life and psychological outcomes among cardiac patients. Int J Public Health. 2009;54(4):233-240.

31. De Smedt D, Clays E, Doyle F, et al. Validity and reliability of three commonly used quality of life measures in a large European population of coronary heart disease patients. Int J Cardiol. 2013;167(5):2294-2299.

32. Dempster M, Donnelly M. A Comparative Analysis of the SF-12 and the SF-36 among Ischaemic Heart Disease Patients. J Health Psychol. 2001;6(6):707-711.

33. Ware JE. SF-36 Health Survey: Manual and Interpretation Guide. Boston, MA: The Health Institute, New England Medical Center; 1997.

34. Bufe A, Wolfertz J, Dinh W, et al. Gender-based differences in longterm outcome after ST-elevation myocardial infarction in patients treated with percutaneous coronary intervention. J Womens Health (Larchmt). 2010;19(3):471-475.

35. Department of Clinical Epidemiology, Aarhus University Hospital. [Myocardial Infarcation-Occurrence and Prognosis. A Study of Firsttime Admissions in Region North Jutland and Region Middle Jutland]. Aaruhus: Aarhus University Hospital; 2008. Available from: http://www.kea.au.dk/ file/pdf/43.pdf. Accessed September 15, 2014. Danish.

36. Sjauw KD, Stegenga NK, Engstrom AE, et al. The influence of gender on short- and long-term outcome after primary PCI and delivered medical care for ST-segment elevation myocardial infarction. EuroIntervention. 2010;5(7):780-787.

37. Bjørner JB, Trab Damsgaard M, Watt T, et al. [Danish Manual for SF-36: A Questionaire about Health-Status]. [S.1.]: Lif; 1997. Danish.

38. Denvir MA, Lee AJ, Rysdale J, et al. Influence of socioeconomic status on clinical outcomes and quality of life after percutaneous coronary intervention. J Epidemiol Community Health. 2006;60(12):1085-1088.

\section{Dovepress}

systematic reviews, risk \& safety of medical interventions, epidemiology \& biostatistical methods, and evaluation of guidelines, translational medicine, health policies \& economic evaluations. The manuscript management system is completely online and includes a very quick and fair peer-review system, which is all easy to use. 